\title{
Induction of cell death in a glioblastoma line by hyperthermic therapy based on gold nanorods
}

This article was published in the following Dove Press journal:

International Journal of Nanomedicine

16 March 2012

Number of times this article has been viewed

\section{Tamara Fernandez \\ Cabada ${ }^{1,2, *}$ \\ Cristina Sanchez Lopez de \\ Pablo 1,3,* \\ Alberto Martinez Serrano ${ }^{2}$ \\ Francisco del Pozo \\ Guerrero 1,3 \\ Jose Javier Serrano \\ Olmedo ${ }^{1,3, *}$ \\ Milagros Ramos Gomez ${ }^{1-3, *}$ \\ 'Centre for Biomedical Technology, Universidad Politecnica de Madrid, Madrid, Spain; ${ }^{2}$ Centre for Molecular Biology, "Severo Ochoa" Universidad Autonoma de Madrid, Madrid, Spain; ${ }^{3}$ Biomedical Research Networking Center in Bioengineering Biomaterials and Nanomedicine (CIBER-bbn), Zaragoza, Spain. \\ *These authors contributed equally to this work}

Correspondence: Milagros Ramos Gomez Centro de Tecnología Biomédica, Parque Científico y Tecnológico de la Universidad Politecnica de Madrid, Campus de Montegancedo, 28223 Pozuelo de Alarcón, Madrid, Spain $\mathrm{Tel}+3491336465$ I

Fax +34913366828

Email milagros.ramos@ctb.upm.es
Background: Metallic nanorods are promising agents for a wide range of biomedical applications. In this study, we developed an optical hyperthermia method capable of inducing in vitro death of glioblastoma cells.

Methods: The procedure used was based on irradiation of gold nanorods with a continuous wave laser. This kind of nanoparticle converts absorbed light into localized heat within a short period of time due to the surface plasmon resonance effect. The effectiveness of the method was determined by measuring changes in cell viability after laser irradiation of glioblastoma cells in the presence of gold nanorods.

Results: Laser irradiation in the presence of gold nanorods induced a significant decrease in cell viability, while no decrease in cell viability was observed with laser irradiation or incubation with gold nanorods alone. The mechanism of cell death mediated by gold nanorods during photothermal ablation was analyzed, indicating that treatment compromised the integrity of the cell membrane instead of initiating the process of programmed cell death.

Conclusion: The use of gold nanorods in hyperthermal therapies is very effective in eliminating glioblastoma cells, and therefore represents an important area of research for therapeutic development.

Keywords: laser irradiation, photothermal therapy, surface plasmon resonance, cancer

\section{Introduction}

Currently, about 10 million people develop cancer every year, and that number is projected to grow to 15 million by $2020 .{ }^{1}$ Therefore, the cost of standard therapies such as radiotherapy, chemotherapy, and/or surgery is expected to increase in the future. The aim of this study was to evaluate alternative therapeutic strategies against cancer.

Hyperthermia is a noninvasive anticancer approach in which biological tissues are exposed to temperatures higher than normal $\left(41^{\circ} \mathrm{C}-47^{\circ} \mathrm{C}\right)$ to promote selective destruction of abnormal cells. ${ }^{2}$ Because of their poor vascular network and reduced heat tolerance, tumors are selectively destroyed in this temperature range. Hyperthermia causes irreversible cell damage by denaturing proteins, which affects the structure of the cell membrane. Thus, hyperthermia for anticancer treatment could inhibit tumor cell proliferation by destroying cancer cells or making them more sensitive to the effects of conventional antitumor therapies, such as radiation or chemotherapy. ${ }^{3}$

Various heating sources ranging from radiofrequency to microwaves, ${ }^{4,5}$ as well as ultrasound waves, ${ }^{6}$ have been used to produce moderate heating in a specific target region. However, the use of heating sources conventionally employed for hyperthermia is limited because of the damage they cause to surrounding healthy tissues. 
Nanomedicine, defined as the use of materials with dimensions in the nanometric scale range for a specific diagnostic or therapeutic purpose, has been progressing rapidly in recent years. Among the current well-developed nanoscaled biomaterials, gold nanostructures have been recognized as promising materials for biomedical applications, including imaging, drug delivery and hyperthermia therapy, due to their biocompatibility and optical tunability. ${ }^{7}$ Recently, gold nanoparticles, in combination with laser light, have been used successfully to achieve controlled thermal damage in tumor tissue ${ }^{8,9}$ Gold nanostructures possess a unique optical property, ie, they strongly absorb light due to surface plasmon resonance converting absorbed light into localized heat. ${ }^{10}$ This strategy has been used to develop thermotherapies for cancer treatment. When a gold particle is exposed to light, the electromagnetic field induces a collective coherent oscillation of the conduction band electrons at the metal surface, forming a charged space which acts as an oscillating dipole along the direction of the electric field. Under certain conditions, the amplitude of the oscillation reaches a maximum, yielding a surface plasmon resonance. The resonance frequency is highly dependent on a number of factors, such as particle size, shape, structure, composition, and the dielectric constant of the surrounding medium. When surface plasmon resonance takes place, there is strong absorption of energy from the irradiating light, as well as light scattering. According to the Mie theory, the ratio of scattering to absorption increases with size, explaining why smaller nanoparticles are preferred for hyperthermic therapies in which light is absorbed by particles and converted into heat. The lattice cools off by passing its heat to the surrounding medium via phonon-phonon relaxation within $100 \mathrm{psec}$. Such fast energy conversion and dissipation can be used to kill cancer cells. This is generally done using continuous wave lasers to allow heat dissipation from the particles to the surrounding medium. ${ }^{11}$

Compared with conventional spherical gold nanoparticles, gold nanorods have shown greater potential for biomedical applications, especially for cancer hyperthermia. Gold nanorods are of special interest because they have large light absorption cross-sections. Gold nanorods exhibit two distinct surface plasmon oscillations, ie, a strong band in the near infrared region, corresponding to electron oscillation along the long axis (longitudinal band), and a weak band in the visible region (transverse band). ${ }^{12}$ Only the longitudinal band is sensitive to size changes, and can be shifted from visible to near infrared by adjusting the aspect ratio (length/ width) during the process of synthesis. ${ }^{12}$ The size, shape, and geometry of the nanostructures are parameters that should be closely controlled, because minute changes may cause a noticeable frequency shift of the surface plasmon resonance band and therefore a decrease in heat generation.

Gold nanostructures, as highly biocompatible nanomaterials, have attracted much interest as hyperthermia agents. Several proof-of-concept studies have been reported for gold nanostructures as hyperthermia agents, using coreshell, ${ }^{13}$ rod-shaped, ${ }^{14-18}$ and branched nanocrystals, ${ }^{19}$ as well as polygonal gold nanoparticles. ${ }^{20}$ The effectiveness of gold nanorods in causing photothermal tumor destruction has been demonstrated even after a single dose treatment. ${ }^{17}$ In addition, gold nanorods functionalized with molecules to target cancer cells have proven highly effective. Gold nanorods have been conjugated to antibodies specifically to target and destroy different types of human carcinomas. ${ }^{21,22}$ Gold nanorods functionalized with folate have been used for photothermal therapy of oral cancer cells. Folate biofunctionalization results in accumulation of gold nanorods on the cell surface, rendering the tumor cells highly susceptible to photothermal damage. ${ }^{8}$ Other nanostructures, such as gold nanocages, have been used successfully to target cancer cells, achieving effective destruction of breast cancer cells. ${ }^{23,24}$

Here we present an early approach to the application of optical hyperthermia based on gold nanorods and laser irradiation, capable of inducing in vitro cell death in a glioblastoma cell line. The results provide essential information to help improve photothermal therapy for glioblastoma tumors in future clinical trials.

\section{Materials and methods Hyperthermia device}

The continuous wave laser (MDL H808, PSU-H-LED power source; Changchung New Industries, Changchun Jilin, China) works at $808 \mathrm{~nm}$, with a maximum output power of $5 \mathrm{~W}$, a beam height from base of $29 \mathrm{~mm}$, a beam diameter at aperture of $5-8 \mathrm{~mm}^{3}$, and laser head dimensions of $155 \times 77 \times 60 \mathrm{~mm}^{2}$. The gold nanorods used in the hyperthermia experiments (30-10-808 Nanorodz; Nanopartz, Salt Lake City, UT) were tuned to the laser source, with a surface plasmon resonance peak (longitudinal band) at $808 \mathrm{~nm}$. The gold nanorods were dispersed in deionized water $(36 \mu \mathrm{g} / \mathrm{mL})$ with $<0.1 \%$ ascorbic acid and $<0.1 \%$ cetyltrimethylammonium bromide (CTAB) surfactant capping agent, and had an axial diameter of $10 \mathrm{~nm}$ and a length of $41 \mathrm{~nm}$. Temperature control was achieved using a precision thermometer (F100; Automatic Systems Laboratories, Redhill, UK). The laser was connected to the system via a multimode optical fiber with a core diameter of $600 \mu \mathrm{m}$, 
a length of $1.5 \mathrm{~m}$, and a power transmission of $90 \%-99 \%$ (600 $\mu \mathrm{m}$ MM fiber; Changchung New Industries). The optical fiber was fixed vertically with the aid of a tripod stand and a burette clamp. The laser light from the fiber irradiated the samples through a collimating lens (78382; Newport, Irvine, CA), which was in direct contact with the lid of the four-well plate containing the samples in each experiment. The samples had a starting temperature of $36^{\circ} \mathrm{C}-37^{\circ} \mathrm{C}$ and a total volume of $500 \mu \mathrm{L}$, and were irradiated with the laser for a period of 20 minutes at $1.2 \mathrm{~W}$.

\section{Cell cultures}

Human brain astrocytoma cells (1321N1; ECACC 86030402) were maintained in Dulbecco's modified Eagle's medium supplemented with $10 \%$ heat-inactivated fetal bovine serum, $2 \mathrm{mM}$ L-glutamine, $100 \mathrm{U} / \mathrm{mL}$ penicillin, and $100 \mu \mathrm{g} / \mathrm{mL}$ streptomycin (Life Technologies, Grand Island, NY). The cell line was maintained at $37^{\circ} \mathrm{C}$ in $5 \% \mathrm{CO}_{2}$ and $95 \%$ air in a humidified atmosphere and passaged twice a week.

\section{Hyperthermia treatments}

The gold nanorods were centrifuged at $1500 \mathrm{rpm}$ for 5 minutes and resuspended at $36 \mu \mathrm{g} / \mathrm{mL}$ in cell culture medium (Dulbecco's modified Eagle's medium supplemented with $10 \%$ heat-inactivated fetal bovine serum, $2 \mathrm{mM} \mathrm{L}$-glutamine, $100 \mathrm{U} / \mathrm{mL}$ penicillin, and $100 \mu \mathrm{g} / \mathrm{mL}$ streptomycin). The $1321 \mathrm{~N} 1$ cells incubated with and without gold nanorods at $36 \mu \mathrm{g} / \mathrm{mL}$ were exposed to laser irradiation at $1.2 \mathrm{~W}$. Controls, $1321 \mathrm{~N} 1$ cells, and $1321 \mathrm{~N} 1$ cells incubated with $36 \mu \mathrm{g} / \mathrm{mL}$ gold nanorods for 20 minutes were run in parallel. After hyperthermia treatment, the $1321 \mathrm{~N} 1$ cells were washed in $1 \times$ phosphate-buffered saline to eliminate the gold nanorods, and were cultured for 24 hours under standard conditions for recovery.

\section{Immunocytochemistry}

Twenty-four hours after hyperthermia treatment, the cells were washed in phosphate-buffered saline and fixed in 4\% paraformaldehyde in phosphate buffer $(\mathrm{pH} 7.5)$, blocked for one hour in $10 \%$ normal goat serum, $0.25 \%$ Triton X-100 in phosphate-buffered saline, and incubated overnight at $4^{\circ} \mathrm{C}$ with an activated caspase-3 antibody (1:100; Cell Signaling Technology, Beverly, MA) followed by incubation with a goat antirabbit IgG antibody conjugated to cyanine 3 (excitation $550 \mathrm{~nm}$; emission $570 \mathrm{~nm}, 1: 100$; Jackson ImmunoResearch Laboratories Inc, West Grove, PA). Cell nuclei were counterstained with Hoechst 33258 (0.2 mg/mL; Molecular Probes, Eugene, OR). To induce apoptosis, the $1321 \mathrm{~N} 1$ cells were treated with $1 \mathrm{mM}$ staurosporine (Sigma, St Louis, MO) for 4 hours before being fixed in 4\% paraformaldehyde. Images were captured using a Zeiss LSM510 confocal microscope (Carl Zeiss, Thornwood, NY).

\section{Cell viability assays MTT assays}

To evaluate the biocompatibility of the gold nanorods, cell viability was measured following incubation of the $1321 \mathrm{~N} 1$ cells with gold nanorods at various concentrations, ranging from 0.036 to $36 \mu \mathrm{g} / \mathrm{mL}$ for 12 and 24 hours. For the viability assays, cells were seeded into 96 -well plates $\left(1 \times 10^{4}\right.$ cells/well; four replicates for each condition); 24 hours later, the cells were treated with gold nanorods at the previously specified concentrations and periods of time. The cultures were then washed twice in phosphate-buffered saline to remove any residual gold nanorods and the tetrazolium dye, 3-(4,5-dimethilthiazol-2)-2,5-diphenyl-2H-tetrazolium bromide (MTT, $5 \mathrm{mg} / \mathrm{mL}$ in phosphate-buffered saline; Sigma), was added to the medium for 45 minutes. After removal of the medium, the precipitated formazan crystals were dissolved in optical grade dimethyl sulfoxide $(200 \mu \mathrm{L})$. The absorbance of each well was measured spectrophotometrically at $570 \mathrm{~nm}$.

\section{Calcein-acetomethoxy/propidium iodide cell survival assays}

The 13211 cells were seeded in P24 wells at an initial density of $5 \times 10^{4}$ cells $/ \mathrm{cm}^{2}$. Cell cultures were irradiated with a laser power source delivering $1.2 \mathrm{~W}$, in the absence and presence of $36 \mu \mathrm{g} / \mathrm{mL}$ gold nanorods for 20 minutes. As a control, the cells were incubated in culture medium alone and in culture medium with $36 \mu \mathrm{g} / \mathrm{mL}$ gold nanorods. Twentyfour hours after hyperthermic treatment, cell viability was determined using a calcein/propidium iodide dual-staining assay (Invitrogen, Molecular Probes). Briefly, the cell culture medium was removed and the cells were rinsed with phosphate-buffered saline. Next, $1 \mu \mathrm{M}$ calcein and $2 \mu \mathrm{M}$ propidium iodide were added in each well and incubated at $37^{\circ} \mathrm{C}$ for 20 minutes. Fluorescence was evaluated using an inverted Leica DMIRB microscope equipped with a digital camera, Leica DC100 (Leica, Nussloch, Germany).

\section{Cell death quantification by flow cytometry analysis}

Cell death was quantified by staining with propidium iodide (Invitrogen) following treatment with laser, gold nanorods, or laser plus gold nanorods, as specified above. Twenty-four hours after hyperthermia treatment, the cells were harvested with Tris-EDTA buffer and centrifuged at $1500 \mathrm{rpm}$ for 
7 minutes at room temperature. Cells were suspended in $1 \mathrm{~mL}$ of phosphate-buffered saline, and $2.5 \mu \mathrm{g} / \mathrm{mL}$ of propidium iodide was added. The samples were then analyzed using a flow cytometer (FACSCalibur System; BD Biosciences, San Jose, CA). To determine the percentage of necrotic cells relative to the total number of cells, 10,000 events were acquired per sample using CELLQuest software (BD Biosciences). All flow cytometry data were analyzed with FlowJo software. Samples were run in triplicate.

\section{Lactate dehydrogenase assays}

The $1321 \mathrm{~N} 1$ cells were seeded at an initial density of $5 \times 10^{4}$ cells $/ \mathrm{cm}^{2}$ in 24 -well culture plates. Cell cultures were either irradiated for 20 minutes with laser or with laser in the presence of $36 \mu \mathrm{g} / \mathrm{mL}$ gold nanorods. Controls were performed by incubating cells in culture medium alone and in culture medium with $36 \mu \mathrm{g} / \mathrm{mL}$ of gold nanorods. After exposure to the different treatments, the $1321 \mathrm{~N} 1$ cells were cultured for 24 hours under standard conditions for recovery. The culture medium was then collected and the lactate dehydrogenase released into the medium was quantified using a cytotoxicity detection kit (Roche, Nutley, NJ), following the manufacturer's instructions. Briefly, culture supernatants were collected and centrifuged at $1500 \mathrm{rpm}$ for 5 minutes to remove the cells. The cell-free supernatants were incubated with the substrate mixture in the kit. Lactate dehydrogenase activity was determined in a coupled enzymatic reaction; during this reaction, the tetrazolium salt is reduced to formazan. The formazan dye was quantified spectrophotometrically at $490 \mathrm{~nm}$.

\section{Uptake studies}

To determine the uptake of gold nanorods by $1321 \mathrm{~N} 1$ cells, confocal laser scanning microscopy and transmission electron microscopy analysis was performed.

\section{Confocal laser scanning microscopy}

For phase contrast microscopy observations, an initial density of $5 \times 10^{4}$ cells $/ \mathrm{cm}^{2}$ was seeded onto glass coverslips in 24-well plates and allowed to grow for 24 hours prior to adding $36 \mu \mathrm{g} / \mathrm{mL}$ of gold nanorods. After 12 hours of incubation in the presence of gold nanorods, the medium was removed, washed twice with phosphate-buffered saline solution, fixed with 4\% paraformaldehyde in phosphate-buffered saline for 15 minutes at room temperature, and washed with phosphatebuffered saline solution again. Phalloidin (1:500; Sigma) was used for staining the cell cytoskeletons. Nuclei were counterstained with ToPro (1:500; Invitrogen). Images were captured using a Zeiss LSM510 confocal microscope. Intracellular gold nanorods were visualized under the same microscope with a confocal reflectance mode. Using this mode, gold nanorods were detected by reflection under excitation with a laser line of $488 \mathrm{~nm}$ and by collecting the emission in the 480-500 nm range.

\section{Transmission electron microscopy}

The $1321 \mathrm{~N} 1$ cells were seeded into 6-well plates. After incubation with gold nanorods $(36 \mu \mathrm{g} / \mathrm{mL})$ for 12 hours, the medium was removed, and the cells were washed with phosphate-buffered saline $1 \times$ solution. The cells were fixed in $4 \%$ paraformaldehyde and $2 \%$ glutaraldehyde in

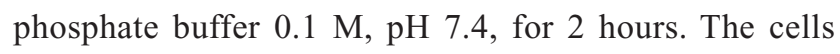
were then scraped from the culture dish and centrifuged at $1500 \mathrm{rpm}$ for 5 minutes; the supernatant was removed. Cell pellets were embedded in Epon Araldite resin (polymerization at $65^{\circ} \mathrm{C}$ for 15 hours). Thin sections $(70 \mathrm{~nm})$ containing cells incubated with gold nanorods were placed on the grids and stained for one minute each with $4 \%$ uranyl acetate ( $1: 1$, acetone:water) and $0.2 \%$ Reynolds lead citrate (water), and then air-dried. Images were obtained using a JEOL JEM1010 transmission electron microscope (Tokyo, Japan).

\section{Statistical analysis}

The results are shown as the mean \pm standard error of the mean of data from three to four experiments. The data were analyzed by single factor analysis of variance followed by the post hoc Tukey's honestly significant difference test. A significance level of $P<0.05$ was chosen, and Statistica 7.0 (StatSoft Inc, Tulsa, OK) software was used for all statistical tests.

\section{Results}

\section{Preliminary heating experiments}

The hyperthermia treatment described in this work consists of continuous wave laser irradiation of samples for 20 minutes at $1.2 \mathrm{~W}$ (diode current 1.6 A). Preliminary experiments, for which a temperature sensor (F100 Precision Thermometer; Automatic Systems Laboratories, Redhill, UK) was used to obtain the corresponding heating curves during laser irradiation, showed that under the same conditions set for the in vitro experiments, hyperthermia treatment allows temperatures of over $50^{\circ} \mathrm{C}$ to be reached in the presence of gold nanorods and below $39^{\circ} \mathrm{C}$ in samples without nanorods (Figure 1). These results indicate that the selected laser power does not induce hyperthermia without the gold nanorods. 


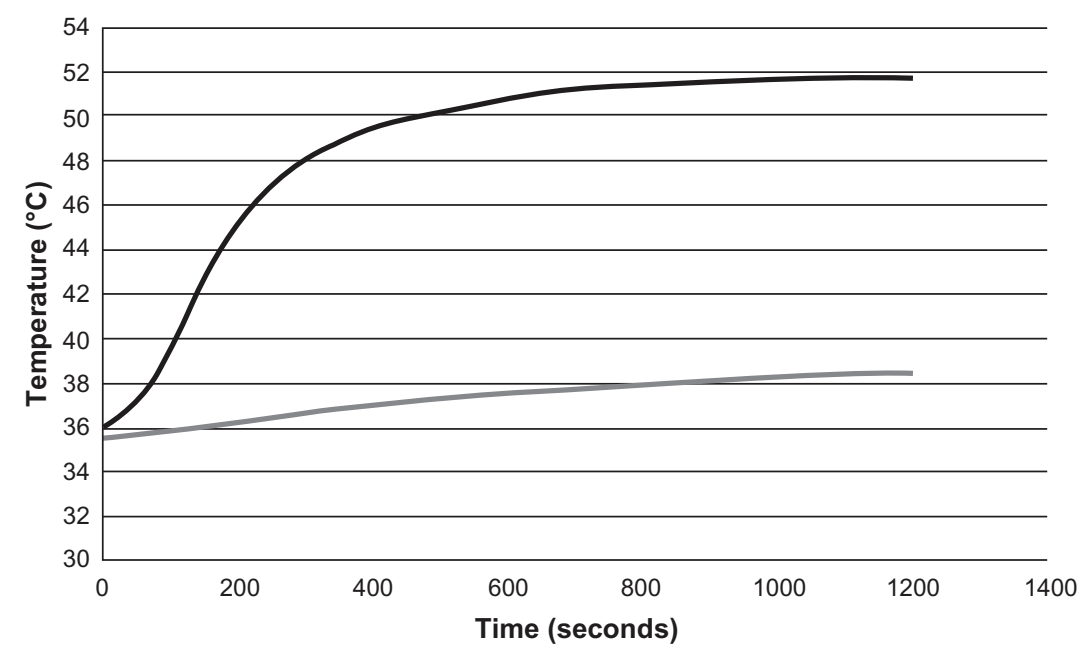

Figure I Heating curves from preliminary experiments: culture medium + gold nanorods + laser (black curve), culture medium + laser (gray curve).

\section{In vitro biocompatibility of gold nanorods}

The MTT cell viability assay was used to evaluate the biocompatibility of the gold nanorods. Increasing concentrations of gold nanorods were assayed to determine their potential cellular toxicity. Incubation of $1321 \mathrm{~N} 1$ cells at concentrations ranging from 0.036 to $3.6 \mu \mathrm{g} / \mathrm{mL}$ for 12 or 24 hours did not significantly affect their viability. A significant decrease in cell viability was observed at 12 and 24 hours only at the highest concentration of nanorods $(36 \mu \mathrm{g} / \mathrm{mL})$. At this concentration, viability of the 1321N1 cells dropped by approximately $60 \%$ (Figure 2 ).

\section{Internalization of gold nanorods by glioblastoma cells}

The ability of gold nanorods to internalize tumor cells was assessed by confocal fluorescence and electron microscopy. After exposing the $1321 \mathrm{~N} 1$ cells to gold nanorods for 12 hours, the presence of gold nanorods inside the cells was detected by reflection (Figure 3A). The intracellular presence

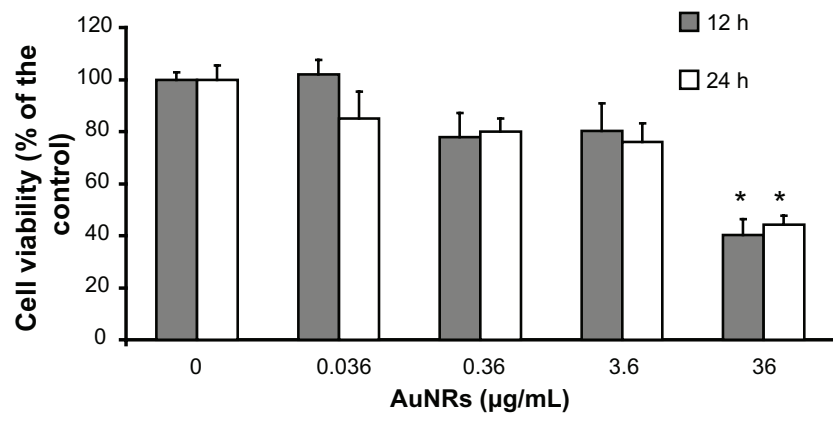

Figure 2 Viability of 132 INI cells exposed to increasing concentrations of gold nanorods for 12 and 24 hours, as evaluated by MTT assay.

Notes: Each value represents the mean \pm standard deviation of three independent experiments. Analysis of variance, post hoc Newman-Keuls test, and $* p<0.05$ compared with untreated control cells. of gold nanorods was revealed by sectioning the confocal stack images along the $\mathrm{XZ}$ and $\mathrm{YZ}$ planes; the orthogonal projections show gold nanorods inside $1321 \mathrm{~N} 1$ cells (green, Figure 3A). The cellular cytoskeleton was stained with phalloidin. When $1321 \mathrm{~N} 1$ cells were incubated with gold nanorods for 2 hours, nanorods were not detected within the nuclei (data not shown). However, when $1321 \mathrm{~N} 1$ cells were incubated for 12 hours with gold nanorods, although most nanorods remained in the cytoplasm, some could be visualized within the nuclei (counterstained with ToPro).

Cellular uptake of gold nanorods was also demonstrated by transmission electron microscopy in 1321N1 cells which had been previously incubated with $36 \mu \mathrm{g} / \mathrm{mL}$ gold nanorods for 12 hours. The length and diameter of the gold nanorods were confirmed by transmission electron microscopy, showing that nanorods were monodispersed even inside the cells. Gold nanorods were seen as electron-dense structures in the cytoplasm of glioblastoma cells (Figure 3B and C). Gold nanorods were localized in membrane-bound structures (arrows in Figure 3B and C), indicating that they were encapsulated inside cytoplasmic organelles rather than dispersed throughout the cytoplasm. Gold nanorods were localized in subcellular organelles with a morphology compatible with endosomes and/or lysosomes.

\section{Cytotoxicity induced by laser irradiation in presence of gold nanorods}

The necrotic effect of laser irradiation on $1321 \mathrm{~N} 1$ cells in the presence of $36 \mu \mathrm{g} / \mathrm{mL}$ gold nanorods was investigated. Cells were irradiated with laser for 20 minutes at $1.2 \mathrm{~W}$ (diode current of 1.6 A). Cell viability after laser irradiation was tested using four different methods: cell death 

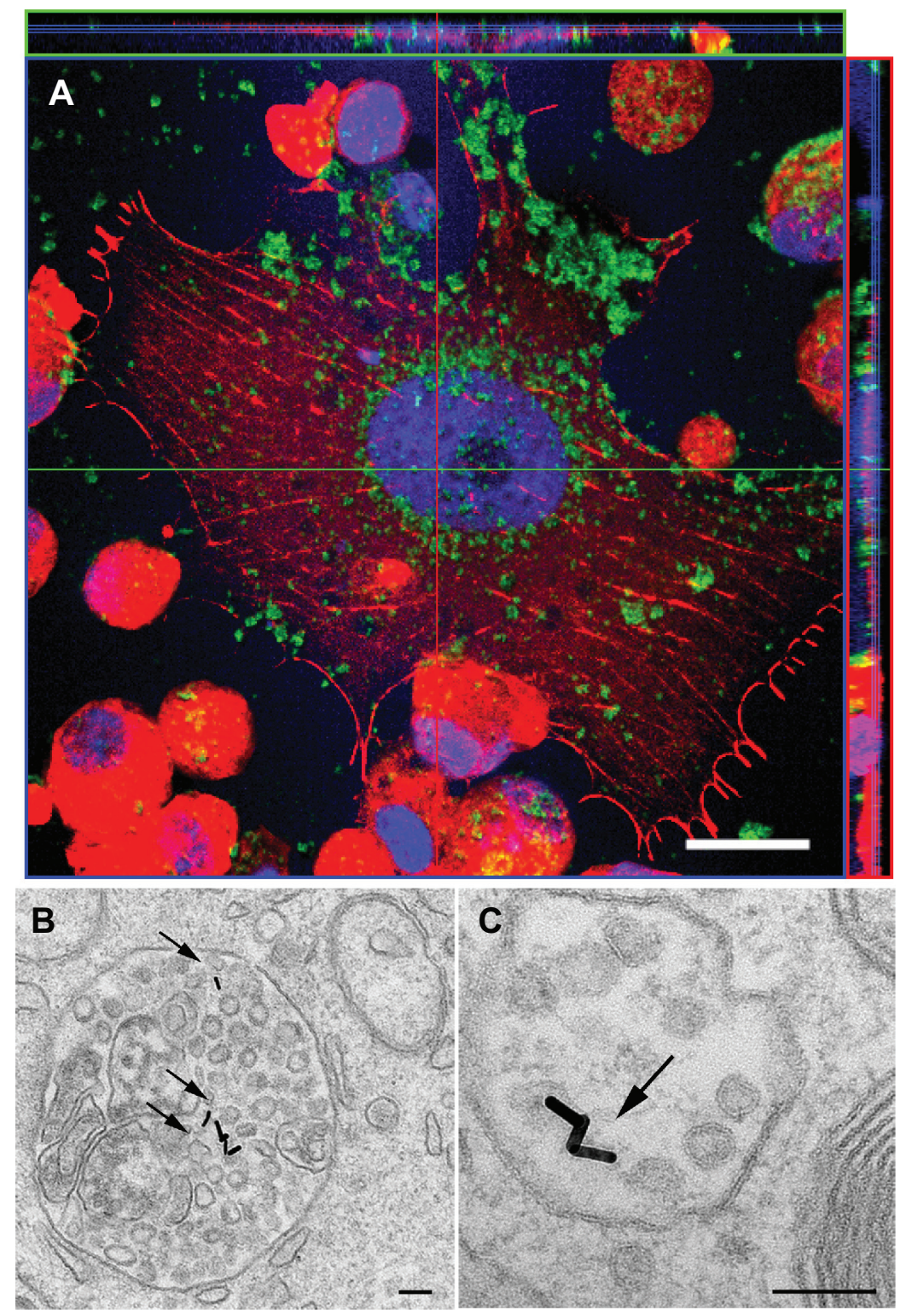

Figure 3 Localization of gold nanorods in $132 \mathrm{INI}$ cells by confocal laser scanning $(\mathbf{A})$ and transmission electron (B and $\mathbf{C}) \mathrm{microscopy}$. (A) Cells were exposed to $36 \mu \mathrm{g} / \mathrm{mL}$ gold nanorods for 12 hours. After fixation, the cells were stained with phalloidin (red) and the nuclei were counterstained with ToPro-3 (blue). Gold nanorods were detected by reflectance (green). Images show that the gold nanorods (green) were effectively internalized into the cytosol of glioblastoma cells and were not excluded from the nuclei. The top and right margin plots in (A) clearly display gold nanorods in the cross-section of the cell (B and $\mathbf{C}$ ). Transmission electron micrographs of gold nanorod-labeled I32INI cells.

Notes: Arrows point to gold nanorods located inside membrane-bound subcellular organelles. Scale bar in (A) $20 \mu \mathrm{m}$. Scale bars in (B) and (C) I00 nm.

quantification by optical fluorescence microscopy after staining $1321 \mathrm{~N} 1$ cells with calcein and propidium iodide (Figure 4); presence of activated caspase-3 (Figure 5); propidium iodide staining to quantify cell death by flow cytometry (Figure 6); and lactate dehydrogenase release assay to analyze the integrity of cell membranes after hyperthermia (Figure 7). The rate of cell death after laser irradiation was compared with that in untreated control cells. Basal cell death caused by the presence of gold nanorods alone or by laser irradiation in the absence of nanorods was also evaluated.

\section{Calcein AM-propidium iodide staining}

Cell viability after hyperthermia treatment was assessed using calcein AM-IP staining. No increase in cell death was observed with laser irradiation in the absence of gold nanorods (Figure 4D) in comparison with the untreated control cells (Figure 4B). In the absence of laser irradiation, gold nanorods had a slight effect on cell viability, as evidenced by a minor increase in the number of cells stained with propidium iodide (Figure 4F). However, irradiation with laser in the presence of $36 \mu \mathrm{g} / \mathrm{mL}$ gold nanorods caused cell death rates of $100 \%$, determined by the absence of calcein-positive 


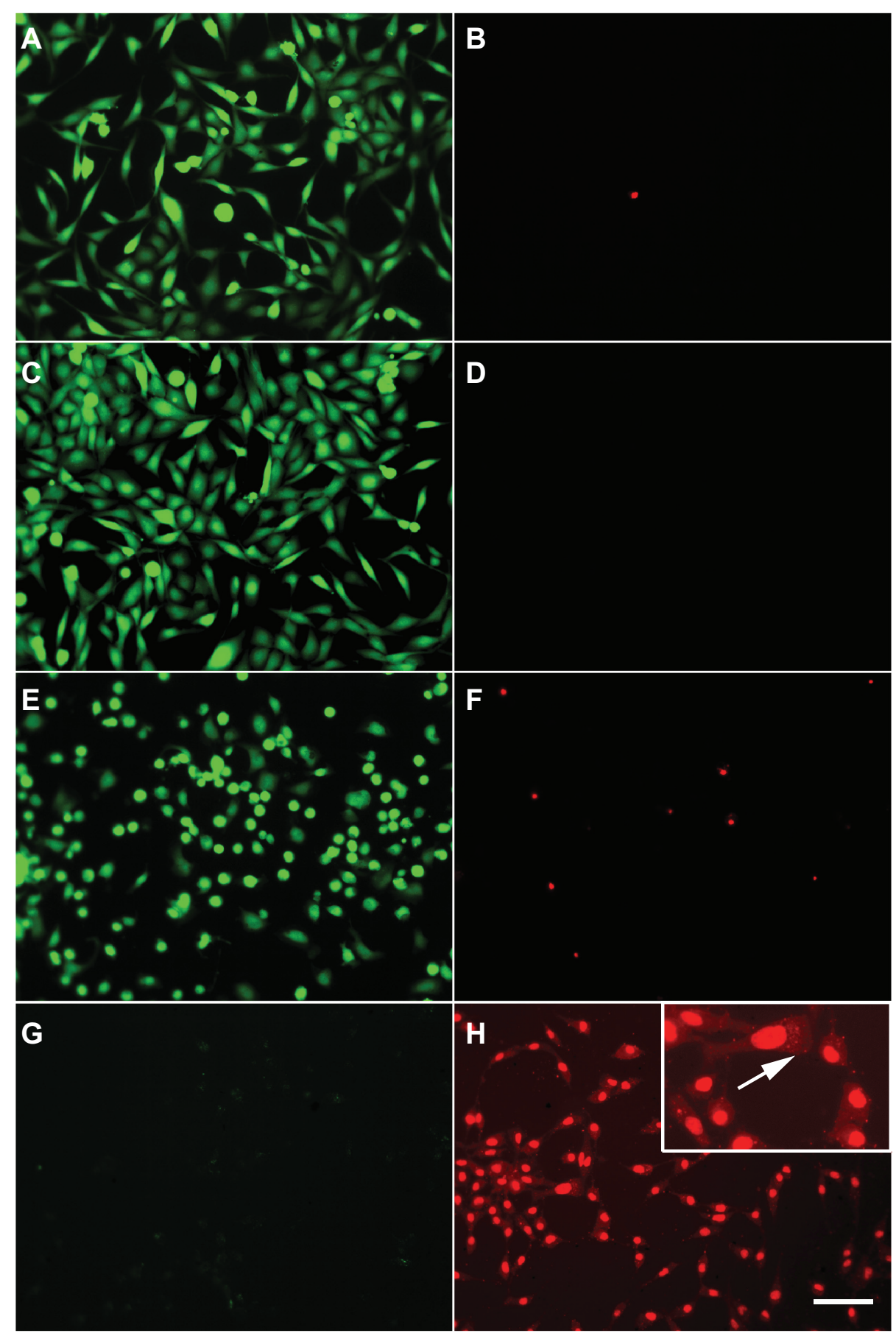

Figure 4 Cell viability after hyperthermia treatments. I32INI cells were stained with calcein and propidium iodide to visualize live (green) and dead (red) cells, respectively. (A and B) Control cells stained with calcein and propidium iodide, respectively. (C and D) I 32INI cells irradiated with laser at I.2W for 20 minutes and subsequently stained with (C) calcein and (D) propidium iodide. (E and F) I32INI cells incubated with $36 \mu \mathrm{g} / \mathrm{mL}$ gold nanorods for 20 minutes and stained for (E) calcein and (F) propidium iodide. (G and $\mathbf{H}$ ) I $32 \mathrm{INI}$ cells incubated with $36 \mu \mathrm{g} / \mathrm{mL}$ gold nanorods and subjected to laser irradiation at $1.2 \mathrm{~W}$ for 20 minutes and then stained for calcein $(\mathbf{G})$ and propidium iodide $\mathbf{( H )}$.

Notes: Inset in $(\mathbf{H})$ shows an area of the same field at a higher magnification. Scale bar $50 \mu \mathrm{m}$.

cells under these experimental conditions (Figure 4G), while all $1321 \mathrm{~N} 1$ cells present in the culture were propidium iodidepositive (Figure 4H).

Propidium iodide staining of $1321 \mathrm{~N} 1$ cells irradiated with laser in the presence of gold nanorods (Figure 4H) was characterized by an apparent fractioning and redistribution of the nuclear material, as evidenced by a scattered pattern of staining, which was not localized in the nucleus but dispersed throughout the entire cell (arrows in inset, Figure 4H). 

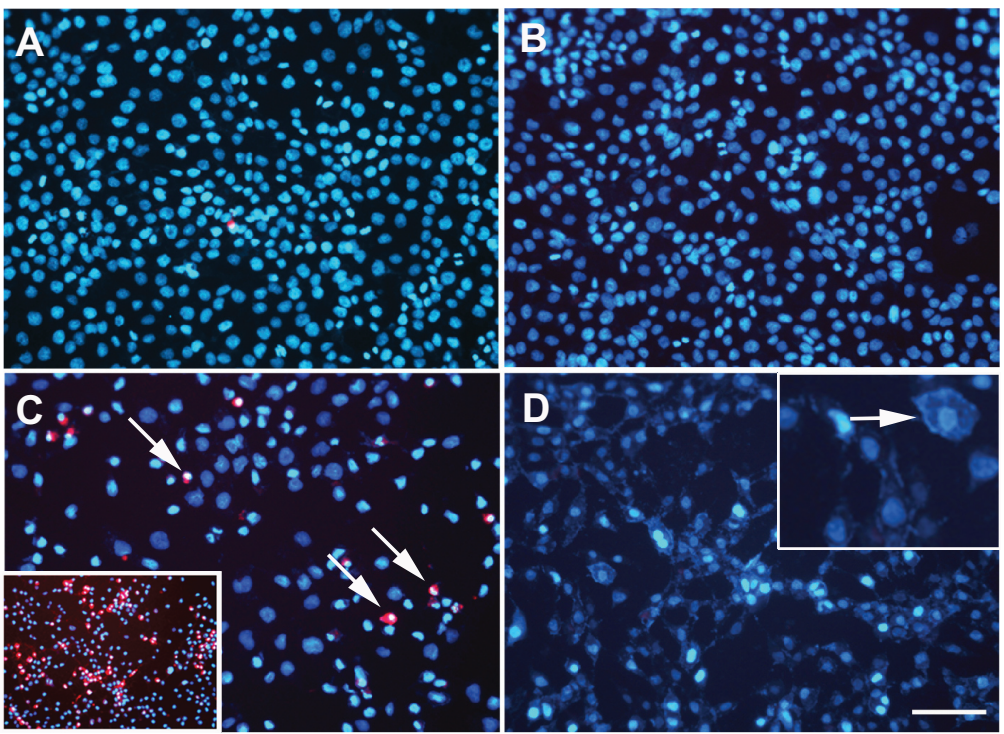

Figure 5 I $32 \mathrm{INI}$ cells stained to detect apoptosis using Hoechst (blue) and antiactivated caspase- 3 antibody (red). (A) Control cells. (B) Cells irradiated with laser at I.2 W for 20 minutes. (C) Cells incubated with $36 \mu \mathrm{g} / \mathrm{mL}$ gold nanorods for 20 minutes. (D) Cells irradiated with laser for 20 minutes in the presence of $36 \mu \mathrm{g} / \mathrm{mL}$ gold nanorods. Notes: Only a few activated caspase-3-positive cells were detected when incubated with gold nanorods, indicated by arrows in (C). Positive cells were present in a very low number compared with the apoptotic cells obtained when cells were treated with staurosporine, in which a high number of caspase-3-positive cells were observed, shown in the inset in (C). No chromatin condensation visualized by Hoechst or activated caspase-3-positive cells were seen in the other conditions tested (A, B, and $\mathbf{D}$ ).

Note: Scale bar, $50 \mu \mathrm{m}$.

\section{Activated caspase-3 staining}

Because nuclear fractioning and cell shrinkage are one of the main morphological characteristics of apoptosis, we studied one of the hallmarks of the apoptotic cascade, namely activation of caspase- 3 , as well as chromatin condensation in the nuclei. To determine whether cell death in response to hyperthermia treatment was due to an apoptotic mechanism or a necrotic one, $1321 \mathrm{~N} 1$ cells were stained with antiactivated caspase-3 antibody and Hoechst dye. The optical images showed that untreated control cells and cells irradiated with laser in absence of gold nanorods (Figure 5A and B, respectively) did not exhibit activated casapase-3 staining and well organized chromatin structures with a homogeneous blue fluorescence staining pattern in their nuclei. Nevertheless, Hoechst staining showed only a few bright and condensed marks (condensed chromatin) in the gold nanorod-treated cells (Figure 5C). Under the same conditions, caspase-3positive staining was observed in some cells (arrows in

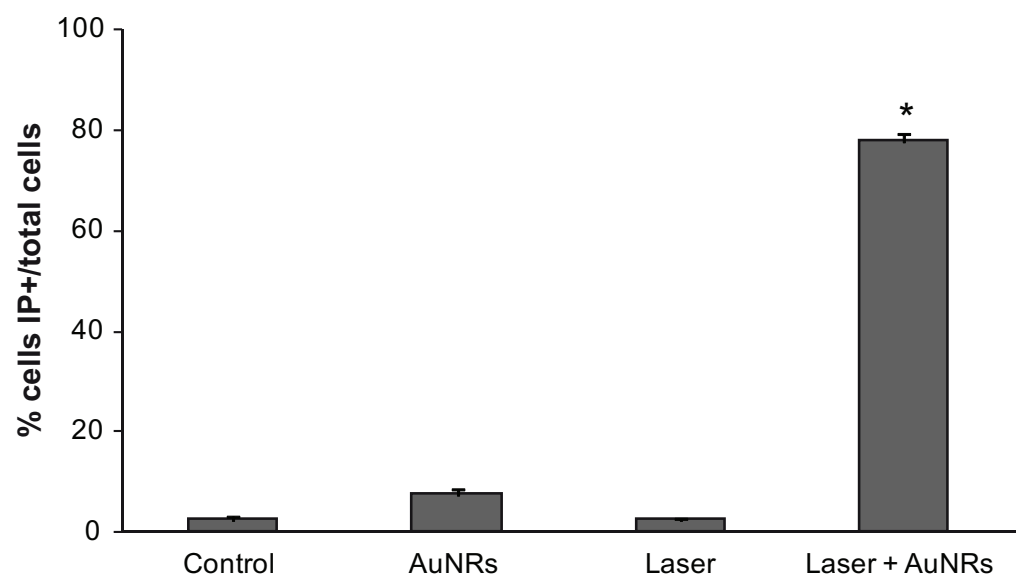

Figure 6 Photothermal treatment of I32INI cells by near infrared irradiation at I.2 W for 20 minutes. Flow cytometry analysis of I32INI cell death by labeling with propidium iodide after hyperthermia treatment. The cells were stained with propidium iodide and then fixed and analyzed on a flow cytometer. The graph shows the percentages of dead cells (IP+-cells) over total cells, calculated for each condition. Control: I32INI basal cell death rate. AuNRs: I32INI cells incubated with $36 \mu g / \mathrm{mL}$ gold nanorods for 20 minutes. Laser: I32 INI cells subjected to laser irradiation at I.2 W for 20 minutes. Laser + AuNRs: I32INI cells subjected to laser irradiation at I.2 W for 20 minutes in the presence of $36 \mu \mathrm{g} / \mathrm{mL}$ gold nanorods.

Notes: Values are the means \pm standard error of the mean of three independent experiments performed in triplicate. $* P<0.005$ versus control cells, analysis of variance, post hoc Tukey's test. 


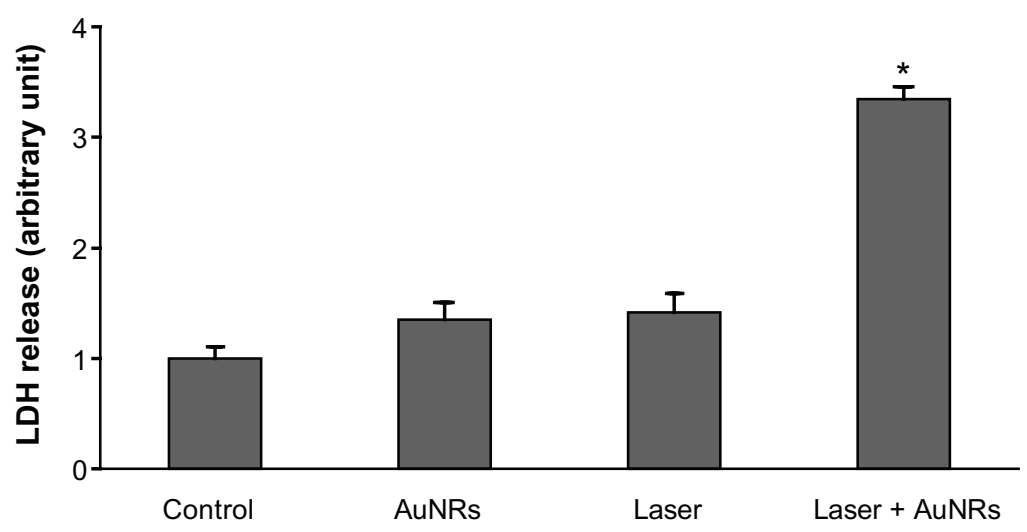

Figure 7 Lactate dehydrogenase released into the culture medium in response to different treatments. Control: A relative value of I was assigned to the lactate dehydrogenase released into the culture medium by $132 \mathrm{INI}$ cells in basal conditions. AuNRs: I32INI cells incubated with $36 \mu \mathrm{g} / \mathrm{mL}$ gold nanorods for 20 minutes. Laser: I32INI cells irradiated with I.2 W laser for 20 minutes. Laser + AuNRs: I32INI cells irradiated with laser at $1.2 \mathrm{~W}$ for 20 minutes in the presence of $36 \mu g / \mathrm{mL}$ gold nanorods.

Notes: Values are the mean \pm standard error of the mean of three independent experiments performed in triplicate. $* P<0.005$ versus control cells, analysis of variance, post hoc Tukey's test.

Figure 5C), although the number was much lower than that obtained when apoptosis was pharmacologically induced with staurosporine (inset in Figure 5C). These data suggest a mild toxic effect on 1321N1 cells when exposed to gold nanorods. Cells irradiated with laser, both in the presence and absence of gold nanorods, showed no apoptotic cells as evidenced by the absence of activated caspase3-positive cells (Figure 5B and D, respectively), and no condensed chromatin was observed when staining nuclei with Hoechst (Figure 5B and D). However, Hoechst staining of cells irradiated with laser in the presence of gold nanorods (Figure 5D) showed a pattern of staining not localized in the nucleus, but labeling of the whole cell (inset in Figure 5D), similar to that obtained with propidium iodide staining (inset in Figure 4H). These results indicate that when cells were irradiated with laser in the presence of gold nanorods, cell death occurred, although not by an apoptotic mechanism, as evidenced by the absence of activated caspase-3-positive cells.

\section{Cell viability analysis by flow cytometry}

Cell viability after laser application was also measured by flow cytometry, using propidium iodide to stain dead cells. When membrane integrity is lost, as seen in the later stages of cell death, propidium iodide staining becomes positive. Significant destruction of $1321 \mathrm{~N} 1$ cells was observed when the cells were exposed to laser irradiation at $1.2 \mathrm{~W}$ for 20 minutes in the presence of $36 \mu \mathrm{g} / \mathrm{mL}$ gold nanorods. Few damaged cells were observed when $1321 \mathrm{~N} 1$ cells were treated with gold nanorods or laser alone (Figure 6). These in vitro results indicate that cancer cells can be destroyed when exposed to gold nanorods in combination with near infrared laser irradiation.

\section{Lactate dehydrogenase release}

The $1321 \mathrm{~N} 1$ cells incubated with gold nanorods were exposed to near infrared laser irradiation and evaluated for photothermal damage. To test laser-induced cell death in response to hyperthermia, the $1321 \mathrm{~N} 1$ cells were irradiated for 20 minutes in the presence or absence of $36 \mu \mathrm{g} / \mathrm{mL}$ gold nanorods. To analyze cell viability after laser irradiation, lactate dehydrogenase released into the medium following loss of cell membrane integrity was quantified. No significant changes in lactate dehydrogenase release were observed when the cells were irradiated with laser for 20 minutes or when exposed only to gold nanorods, compared with control cells (Figure 7). However, the death rate in cells exposed to laser for 20 minutes in the presence of gold nanorods was high, as summarized in Figure 7.

In summary, cell death measured by optical microscopy, flow cytometry, and release of lactate dehydrogenase into the medium confirmed the existence of significant differences in death rate in cells treated with laser in the presence of gold nanorods compared with control cells. These results show that laser treatment for 20 minutes in presence of gold nanorods may induce a near complete death of glioblastoma cells (Figure 4H). Interestingly, treating cells with either gold nanorods or laser irradiation alone did not significantly increase cell death rates. Thus, MDL H808 laser irradiation reduces viability in a glioblastoma cell 1321N1 line only when samples are exposed to the correct concentration of gold nanorods.

\section{Discussion}

We have examined an approach that aims at becoming a proof of concept of an optical hyperthermia system. Two main 
aspects were considered, ie, the instrument and the cell line. The instrument was similar to others currently being used, ${ }^{18,25}$ but with the possibility of using different excitation methods by changing the light exposure pattern from continuous wave light to pulsed light. This system was developed to evaluate the effectiveness of gold nanorods designed to work in the optimal tissue window for light absorbance (808 nm).

Different types of nanoparticles have good plasmon resonance energy, although their efficacy in causing cell death varies depending on their size, shape, and surface coating. This early investigation has been carried out with commercial gold nanorods as a reference and starting point and in a glioblastoma cell line. Thus, the whole procedure for generating optical hyperthermia has been studied.

Glioblastoma multiforme is a common and aggressive brain tumor characterized by an infiltrative nature. Current standard therapy for glioblastoma multiforme consists of surgery followed by radiotherapy combined with chemotherapy. ${ }^{26}$ This chemoirradiation approach results in a significant increase in survival compared with radiotherapy alone. Nevertheless, due to tumor recurrence, the median survival time is still limited to approximately 15 months. Thus, development of new effective therapies is urgently needed. Evidence has shown that cancer cells are more vulnerable to elevated temperatures compared with healthy cells, due to the hypoxic environment and higher metabolic rates. ${ }^{27}$ Numerous clinical studies have demonstrated a marked reduction in tumor size after treatment with localized hyperthermia. ${ }^{28}$

Hyperthermia induced by magnetic nanoparticles in tumor tissues is a potential therapeutic tool with promising results in both preclinical and clinical assays. ${ }^{29}$ Gold nanoparticle-mediated thermal therapy is a new and minimally invasive tool for the treatment of cancer. Gold nanorods have become a class of promising candidates for tumor-targeted thermotherapy due to their strong light-enhanced absorption in the near infrared region and plasmon resonance-enhanced properties. ${ }^{30}$ Gold nanorods are being extensively investigated because of their good stability and biocompatibility. ${ }^{9}$

In the present study, we have used gold nanorods as heatinducing agents after laser radiation to obtain a high death rate of glioblastoma cells. An important concern with all classes of nanoparticles is their toxicity, which is determined by the dose, surface chemistry, and location and duration of confinement to the body. Whereas gold has been used in medicine for many decades, the unique properties and biodistribution of nanoparticle formulations requires systematic evaluation and characterization of biocompatibility. ${ }^{31}$ Our findings indicate that gold nanorods incubated with
$1321 \mathrm{~N} 1$ for short times (20 minutes) did not induce a decrease in cell viability compared with control cells, even at high concentrations. Cell viability was measured by three different methods, ie, microscopically by calcein-propidium iodide staining, by flow cytometry using propidium iodide to calculate the rate of cell death, and finally evaluating the lactate dehydrogenase released into the culture medium in the presence of gold nanorods. No significant increase in the number of dead cells was determined with any of the three methods in comparison with control cells, indicating a lack of cytotoxicity of gold nanorods for short incubation times. Therefore, without laser irradiation, the high doses of gold nanorods used in hyperthermia assays did not produce a decrease in cell viability as seen by calcein and propidium iodide staining, nor did they promote any significant loss of cell membrane integrity as observed by the lactate dehydrogenase assay, although a slight increase in the number of activated casapase-3-positive cells was observed. However, when longer incubation times were tested, a significant decrease in cell viability was observed only at the highest dose tested, both at 12 and 24 hours, as measured by MTT (Figure 2). The toxicity of the surfactant (CTAB) on the surface of the gold nanorods could be responsible for the effect on cell viability at the highest tested dose (Figure 2). For the gold nanorods, cytotoxicity has been previously associated with CTAB-stabilized gold nanorods. ${ }^{32}$ In our model, the decrease in cell viability observed when gold nanorods were added at $36 \mu \mathrm{g} / \mathrm{mL}$ (Figure 2) was avoided by treating gold nanorods with $\mathrm{HCl}$ to eliminate their CTAB coating ${ }^{33}$ (data not shown), confirming that the toxicity was due to the presence of CTAB.

In vitro hyperthermia tests with gold nanorods increase the temperature of the medium, reaching a plateau 10 minutes after laser irradiation (Figure 1). This temperature increase revealed that the gold nanorod-mediated photothermal effect can destroy glioblastoma cells in a very effective manner. After laser application in the presence of the gold nanorods, no calcein-positive cells were observed (Figure 4G) and all $1321 \mathrm{~N} 1$ cells were positive for propidium iodide staining (Figure 4H). Laser application in the absence of gold nanorods or incubation of $13121 \mathrm{~N} 1$ cells with the same concentration of gold nanorods did not produce any cytotoxic effects on $1321 \mathrm{~N} 1$ cells. These results were also confirmed by flow cytometry analysis (Figure 6). To avoid potential bias, we investigated the possible necrotic effect of simple laser irradiation and the cell death rate in the presence of gold nanorods in $1321 \mathrm{~N} 1$ cells. Results show that only the combination of gold nanorods and laser irradiation could kill 
glioblastoma cells. Therefore, these results demonstrate that the effect of hyperthermia was the dominant factor in cell death using our experimental model.

The ability of gold nanorods to internalize $1321 \mathrm{~N} 1$ cells was assessed by confocal fluorescence and electron microscopy imaging, showing that only a small percentage of gold nanorods were internalized by $1321 \mathrm{~N} 1$ cells (Figure 3 ). Subcellular localization of gold nanorods by transmission electron microscopy imaging showed that the internalized gold nanorods subsequently accumulated in subcellular organelles resembling endosomes/lysosomes. These results demonstrate that the gold nanorods did not need to be fully internalized by $1321 \mathrm{~N} 1$ cells to mediate photothermal damage. In fact, more striking hyperthermic effects were obtained when gold nanorods were deposited on the surface of cells, and the cell membrane appears to be the most susceptible cellular component to thermal damage. ${ }^{34}$ Although it has been reported that the energy threshold for cell therapy depends significantly on the number of nanorods taken up per cell, ${ }^{35}$ other authors have shown that cancer cell death may occur in response to extracellular hyperthermia induced by gold nanorods. ${ }^{36}$ Our results indicate that extracellular gold nanorods remaining in the culture medium without being internalized by $1321 \mathrm{~N} 1$ cells could also lead to effective cell destruction within a relative short period of time and using a laser intensity that does not affect cell survival in the absence of gold nanorods.

It is well known that nanoparticles can accumulate at tumors due to the highly permeable vascular network in neoplastic tumors, ie, the so-called "enhanced permeability and retention effect", occurring because of extravasation of nanoparticles from leaky regions of the tumor vasculature. ${ }^{37}$ This effect produces accumulation of nanoparticles in the vicinity of tumor cells. If gold nanorods are not fully internalized by cancer cells, an alternative approach could be to apply laser irradiation to gold nanorods in the extracellular space, which would increase the temperature outside the cancer cells, causing extracellular hyperthermia. This effect has been previously described to produce efficient cancer cell ablation..$^{38}$

The mechanisms involved in the process of cell death mediated by gold nanorods in photothermal ablation remain unresolved. To investigate the nature of cell death caused by laser irradiation, activated caspase-3 and Hoechst staining were performed after hyperthermia treatment, to discriminate between necrotic and apoptotic cell death. Figure $4 \mathrm{G}$ clearly shows that all tumor cells were killed after laser irradiation in the presence of gold nanorods, and that these cells were necrotic, and not apoptotic, as demonstrated by the absence of staining for activated caspase-3 (Figure 5D). The incubation of 1321N1 cells with gold nanorods produced very few caspase-3-positive cells, indicating that these gold nanorods might produce a slight increase in apoptotic cell death. This is probably due to the toxic effect of the CTAB present in the coating of gold nanorods, as previously described. ${ }^{35,38}$ The mechanism by which CTAB induces cytotoxicity has also been described in depth. ${ }^{39} \mathrm{CTAB}$ is a cationic surfactant, and cations may induce mitochondria dysfunction. CTAB molecules can enter cells, damage the mitochondria, and induce apoptosis. In this process, CTAB damages the mitochondrial integrity and triggers release of reactive oxygen species. Subsequently, the apoptotic mitochondrial pathway is initiated, leading to sequential activation of caspases, including caspase-3, which plays a central role in the execution phase of cell apoptosis. ${ }^{39}$ In any case, the few caspase-3-positive cells obtained by incubating glioblastoma cells with gold nanorods occurred at a much lower percentage than when the same cells were treated with staurosporine, a chemical inducer of apoptosis (Figure 5C, inset). However, cells treated with gold nanorods and irradiated by laser for 20 minutes showed no signs of apoptotic cell death, as evidenced by the absence of activated caspase-3-positive cells and no chromatin condensation visualized by Hoechst dye. Our data suggest that photothermal damage causes a significant loss of cell membrane integrity, as evaluated by the lactate dehydrogenase release assay. This is probably due to the rapid necrotic cell death originated by the sharp increase in temperature (over $10^{\circ} \mathrm{C}$ ) produced only 3 minutes after application of laser in the presence of gold nanorods. As the temperature rises, the number of cells undergoing necrosis instead of apoptosis increases. ${ }^{40}$

These positive results are proof of concept of the efficacy of optical hyperthermia. Future studies will be devoted to understanding the local interaction between gold nanorods and the surrounding medium. By changing the conventional continuous wave method for different excitation waves, the total irradiated energy can be reduced while preserving similar results in terms of cell mortality. Possible correlations between nanorod shape and size and the efficacy of the irradiation method should be investigated, as well as the mechanical effects derived from the extremely short heating times of the nanorods. Determination of the physical mechanisms that eventually produce cellular death is essential to develop more effective and efficient optical hyperthermia systems. 


\section{Conclusion}

The use of gold nanorods in hyperthermal therapy is very effective, and an important area of research and therapeutic development. For effective hyperthermia treatment, many parameters still need to be optimized, concerning both laser and gold nanorods, in order to achieve treatments that work as effectively as possible. Gold nanorod surfaces need further modification to make them biocompatible and suitable for imaging and as theragnostic agents for clinical purposes. Promoting the translational potential of gold nanorods as antitumoral agents will require using chemically stable coatings other than CTAB to avoid the cytotoxic effect observed in $1321 \mathrm{~N} 1$ cell cultures. Due to the limited capacity of laser penetration in tissues, the method described here could provide an additional aid to surgery for removing brain tumors completely.

\section{Acknowledgments}

The authors gratefully acknowledge the financial support of the Reina Sofia Foundation. This work was also supported by a European Union EXCELL grant (NMP4SL-2008-214706) and a Spanish Ministry of Science and Innovation grant TEC2009-14272. Dainora Jaloveckas (http://cienciatrad.wordpress.com/) participated in the review of the manuscript.

\section{Disclosure}

The authors report no conflicts of interest in this work.

\section{References}

1. Boyle P, Levin B, editors. World Cancer Report 2008. Lyon, France: International Agency for Research on Cancer Press; 2008.

2. van der Zee J. Heating the patient: a promising approach? Ann Oncol. 2008;13:1173-1184.

3. Svaasand LO, Gomer CJ, Morinelli E. On the physical rationale of laser induced hyperthermia. Lasers Med Sci. 1990;5:121-128.

4. Mirza AN, Fornage BD, Sneige N, et al. Radiofrequency ablation of solid tumors. Cancer J. 2001;7:95-102.

5. Seki T, Wakabayashi M, Nakagawa N, et al. Percutaneous microwave coagulation therapy for patients with small hepatocellular carcinoma, comparison with percutaneous ethanol injection therapy. Cancer. 1999;85:1694-1702.

6. Kremkau FW. Cancer therapy with ultrasound: a historical review. J Clin Ultrasound. 1979;7:287-300.

7. Singh R, Nalwa HS. Medical applications of nanoparticles in biological imaging, cell labeling, antimicrobial agents, and anticancer nanodrugs. J Biomed Nanotechnol. 2011;7:489-503.

8. Huff TB, Tong L, Zhao Y, Hansen MN, Cheng JX, Wei A. Hyperthermic effects of gold nanorods on tumor cells. Nanomedicine (Lond). 2007;2:125-132.

9. Kuo WS, Chang CN, Chang YT, et al. Gold nanorods in photodynamic therapy, as hyperthermia agents, and in near-infrared optical imaging. Angew Chem Int Ed Engl. 2010;49:2711-2715.

10. Jain PK, El-Sayed IH, El-Sayed MA. Au nanoparticles target cancer. Nano Today. 2007;2:16-27.
11. Huang X, El-Sayed MA. Gold nanoparticles: optical properties and implementations in cancer diagnosis and photothermal therapy. Journal of Advanced Research. 2010;1:13-28.

12. Huang X, Jain PK, El-Sayed IH, El-Sayed MA. Plasmonic photothermal therapy (PPTT) using gold nanoparticles. Lasers Med Sci. 2008;23:217-228.

13. Zhang QB, Xie J, Lee JY, Zhang JX, Boothroyd C. Synthesis of Ag@AgAu metal core/alloy shell bimetallic nanoparticles with tunable shell compositions by a galvanic replacement reaction. Small. 2008;4:1067-1071.

14. Samim M, Prashant C, Dinda A, Maitra A, Arora I. Synthesis and characterization of gold nanorods and their application for photothermal cell damage. Int J Nanomedicine. 2011;6:1825-1831.

15. Tong L, Zhao Y, Huff TB, Hansen MN, Wei A, Cheng JX. Gold nanorods mediate tumor cell death by compromising membrane integrity. Adv Mater. 2007;19:3136-3141.

16. Dickerson EB, Dreaden EC, Huang X, et al. Gold nanorod assisted near-infrared plasmonic photothermal therapy (PPTT) of squamous cell carcinoma in mice. Cancer Lett. 2008;269:57-66.

17. Von Maltzahn G, Park JH, Agrawal A, et al. Computationally guided photothermal tumor therapy using long circulating gold nanorods antennas. Cancer Res. 2009;69:3892-3900.

18. Fourkal E, Vlechev I, Taffo A, Ma C, Khazak V, Skobeleva N. Photo-thermal cancer therapy using gold nanorods. IFMBE Proc. 2009;25: 761-763.

19. Hao E, Bailey RC, Schatz GC, Hupp JT, Li S. Synthesis and optical properties of "branched" gold nanocrystals. Nano Lett. 2004;4: 327-330.

20. Malikova N, Pastoriza-Santos I, Schierhorn M, Kotov NA, Liz-Marzan ML. Layer-by-layer assembled mixed spherical and planar gold nanoparticles: control of interparticle interactions. Langmuir. 2002;18:3694-3697.

21. Huang X, El-Sayed I, Qian W, El-Sayed M. Cancer cell imaging and photothermal therapy in the near-infrared region by using gold nanorods. J Am Chem Soc. 2006;128:2115-2120.

22. Hirsch LR, Stafford RJ, Bankson JA, et al. Nanoshell-mediated nearinfrared thermal therapy of tumors under magnetic resonance guidance. Proc Natl Acad Sci U S A. 2003;100:13549-13554.

23. Au L, Zheng D, Zhou F, Li ZY, Li X, Xia Y. A quantitative study on the photothermal effect of immuno gold nanocages targeted to breast cancer cells. ACS Nano. 2008;2:1645-1652.

24. Young JK, Figueroa ER, Drezek RA. Tunable nanostructures as photothermal theranostic agents. Ann Biomed Eng. 2012;40:438-459.

25. Rozanova N, Zhang JZ. Photothermal ablation therapy for cancer based on metal nanostructures. Science in China Series B: Chemistry. 2009;52:1559-1575.

26. Brandes AA, Tosoni A, Franceschi E, Reni M, Gatta G, Vecht C. Glioblastoma in adults. Crit Rev Oncol Hematol. 2008;67:139-152.

27. Overgaard J. Effect of hyperthermia on malignant cells in vivo. A review and a hypothesis. Cancer. 1977;39:2637-2646.

28. Falk MH, Issels RD. Hyperthermia in oncology. Int $J$ Hyperthermia. 2001;17:1-18.

29. Silva AC, Oliveira TR, Mamani JB, et al. Application of hyperthermia induced by superparamagnetic iron oxide nanoparticles in glioma treatment. Int J Nanomedicine. 2011;6:591-603.

30. Huang X, Jain PK, El-Sayed IH, El-Sayed MA. Gold nanoparticles: interesting optical properties and recent applications in cancer diagnostics and therapy. Nanomedicine. 2007;2:681-693.

31. Krishnan S, Diagaradjane P, Cho SH. Nanoparticle-mediated thermal therapy: evolving strategies for prostate cancer therapy. Int J Hyperthermia. 2010;26:775-789.

32. Niidome T, Yamagata M, Okamoto Y, et al. PEG-modified gold nanorods with a stealth character for in vivo applications. J Control Release. 2006;114:343-347.

33. Zong $\mathrm{S}$, Wang $\mathrm{Z}$, Yang J, Cui Y. Intracellular $\mathrm{pH}$ sensing using p-aminothiophenol functionalized gold nanorods with low cytotoxicity. Anal Chem. 2011;83:4178-4183. 
34. Zharov VP, Galitovskaya EN, Johnson C, Kelly T. Synergistic enhancement of selective nanophotothermolysis with gold nanoclusters: potential for cancer therapy. Lasers Surg Med. 2005;37:219-226.

35. Chen CL, Kuo LR, Chang CL, et al. In situ real-time investigation of cancer cell photothermolysis mediated by excited gold nanorod surface plasmons. Biomaterials. 2010;31:4104-4112.

36. Huang HC, Rege K, Heys JJ. Spatiotemporal temperature distribution and cancer cell death in response to extracellular hyperthermia induced by gold nanorods. ACS Nano. 2010;4:2892-2900.

37. Maeda $H$. The enhanced permeability and retention (EPR) effect in tumor vasculature: the key role of tumor-selective macromolecular drug targeting. Adv Enzyme Regul. 2001;41:189-207.
38. Takahashi H, Niidome Y, Niidome T, Kaneko K, Kawasaki H, Yamada S. Modification of gold nanorods using phosphatidylcholine to reduce cytotoxicity. Langmuir. 2006;22:2-5.

39. Qiu Y, Liu Y, Wang L, et al. Surface chemistry and aspect ratio mediated cellular uptake of Au nanorods. Biomaterials. 2010;31:7606-7619.

40. Samali A, Holmberg CI, Sistonen L, Orrenius S. Thermotolerance and cell death are distinct cellular responses to stress: dependence on heat shock proteins. FEBS Lett. 1999;461:306-310.
International Journal of Nanomedicine

\section{Publish your work in this journal}

The International Journal of Nanomedicine is an international, peerreviewed journal focusing on the application of nanotechnology in diagnostics, therapeutics, and drug delivery systems throughout the biomedical field. This journal is indexed on PubMed Central, MedLine, CAS, SciSearch $\AA$, Current Contents ${ } /$ Clinical Medicine,

\section{Dovepress}

Journal Citation Reports/Science Edition, EMBase, Scopus and the Elsevier Bibliographic databases. The manuscript management system is completely online and includes a very quick and fair peer-review system, which is all easy to use. Visit http://www.dovepress.com/ testimonials.php to read real quotes from published authors.

Submit your manuscript here: http://www.dovepress.com/international-journal-of-nanomedicine-journal 